\title{
Considerations on Relation between Philosophy of Sport and Common Sense Thinking
}

Authors' contribution:

A) conception and design of the study

B) acquisition of data

C) analysis and interpretation of data

D) manuscript preparation

E) obtaining funding

\section{Jerzy Kosiewicz}

Josef Pilsudski University of Physical Education in Warsaw, Poland

\section{KEYWORDS}

\begin{abstract}
The purpose of this presentation is not to elaborate on the meaning of the common sense thinking and common sense in relation to cognition sensu stricto that is, in relation to scientific cognition. This topic has already been sufficiently covered in a concise and synchronous way. The focus of this presentation is mainly on selective manifestations of common sense thinking and their penetration of the philosophy in general, as well as the philosophy of sport in particular.

common sense thinking, common sense, colloquialism, scientific cognition, philosophy in general, philosophy of sport
\end{abstract}

\section{Common sense thinking and common sense}

Philosophy (when simplifying its properties) is a fully rational discipline of knowledge or science (with the exception of normative ethics and aesthetics), in which the logical criterion of truth and falsehood is applied to its statements. Therefore, philosophy is fundamentally opposed (with the exception of some historical and already falsified assumptions, concepts, and theories, like for example the views of Thomas Reid \{Reid, 1764 and Reid, 1975\} and the Scottish school of common sense established by him and described for instance in "The Scottish Philosophy of Common Sense" (Grave, 1960) to welcome on its territory views that have both an intuitive and, in the assumption of their authors, not verifiable or not testified character in terms of applying towards those views the logical values. The authors of these views in accordance with the contemporary assessment of the meaning of knowledge based on the common sense thinking and common sense - do not, in fact, seek to determine objective value of their views in terms of logical criteria of truth and falsehood. They rather point out to the existence of the "first principles of reason" that are the inherent features of our psychophysical structure, of which impact we do not fully realize, even though we assumed them in every undertaken thought and action (Hołówka, 1986, p. 27). These authors claim that the first principles of reason cannot be discredited, and "as soon as one understood them, one immediately legitimize them" (Reid, 1974, p. 549). The obvious and irresistibly self-evident light of truth is contained in the statement referring to the principle "and is not borrowed from any other source" (Reid, 1974, p. 549).

Common sense thinking (from the French meaning sense commun) and common sense (or the ability to assess, from the French bon sens), can be treated - according to Teresa Hołówka - as the same thing, or as 
two different things, as indicated by Marcin Czerwiński. On the note, the latter talked about it in the preface to the Hołówka's book (her sensational habilitation thesis) untitled "Common sense thinking" (1986).

Common sense statements contained in the various forms of verbal expressions - for example, statements contained in the journalistic reports and comments on the sports events - often have simply incredible reach and power to influence the audience. They make an unimaginable impact on awareness, perceptions and attitudes of spectators, listeners, viewers, and fans. They are influential, value creating, and shaping people reception of the event. Common sense statements contained verbal expression create almost the entire context of the interpretation for the observed phenomena (and not only for the phenomena related to sports, but also those occurring in social life, family, professional, political, or religious life). These common sense statements having strictly persuasive overtone, get on the very fertile emotional ground.

The minds of recipients are saturated to a greater or lesser extent (rather greater than lesser) with the content of the aforementioned common sense beliefs that are reduced to their social contextual and common perception of the sport as a phenomenon that activates emotions and the cognitive needs. The factual content of common statements is almost beyond social control, that is, beyond the influence of knowledge from the area of social sciences and the natural sciences of sport. It leads spectators to the situation of being limited by the comforting illusions, the half-truths, the banal truths, the eclectic range of opinions on the perceived phenomena, by the supposititious images (Czerwiński, 1986, pp. 6-8) of the world associated with sport.

For the most part the aforementioned beliefs and convictions are typical for the different social contexts and they are legitimized and reproduced by people who belonged to them. These beliefs are, in a way, coherent (even though they are contrary to the assumption of logic as a discipline rooted in philosophy) that is, they are in line with each other; they are in accordance with the content of other, similar statements and statements that precede them. They are in line with the common sense thinking, in line with the resource, circulation and influence of knowledge possessed by the recipients of the statements. These common ideas and opinions arise and gain general consensus due to the alleged accuracy of their judgment; this accuracy is associated with skillfully presented unpretentiousness. They create real interacting amalgamation of the judgments, schematic and common statements. They enjoy getting interest, appreciation, and popularity.

The contexts of justification and related to them arguments, which are utilized by people who are using the common sense and the common sense conceptions, and which are directed against those who criticize these people, have the implicit connotation: suppositious and deliberately hidden. The people who use these common sense concepts imply that they express "the voice of all", that is the alleged truth of the community, which is a kind of common indisputable obviousness: the axiom or even the logical postulate. That "voice of all", according to Theresa Hołówka, sounds as follows:

"The human mind tends to have (...) an inexplicable tendency to rampant theorizing, sophistry, and speculation that are 'divorced from life', so the prevailing consensus is broken every now and then by a handful of madmen and extravagancy of intellectuals. It is also prone to wander and to be blind to the absurdity of its own products. In such cases, the human mind should quickly return to the basic axioms, as there is nothing else that would serve as a certain foundation. It should turn to its inherent, correct cognitive intuitions, which - as it is confirmed by the experience of countless generations - will never deceive him astray" (Hołówka, 1986, p. 15).

This method and style of thinking includes the conviction that the common sense thinking, the common view of the world is the natural foundation of our knowledge. It is accompanied by a persistent belief in the accurate and natural view of the world. The belief in the infallibility of common concepts goes hand in hand with aggression and does not go with the desire for even a cursory - in a strictly cognitive sense that is in a scientific or philosophical sense - description and justification of this belief (Hołówka, 1986, p. 16). 
When common sense thinking is a subject of "critical analysis, it is revealed that the common sense thinking contains a lot of crudity and falsehoods" (Czerwiński, 1986, p. 8). The result of this is a disgrace of common sense thinking. The analysis strikes at the dignity of the statements promulgated by the concerned person and the related social environment - it hits at the objectivity, necessity, and universality of common sense statements. It also falsifies the content, meaning, essence and substantive cognitive value of the common sense concepts, their logical and methodological reasons (because the common sense thinking doesn't has an operative methodology). The analysis exposes ambiguity, tautological character of common sense thinking; it exposes the coexistence of conflicting and unpredictable statements and their "incontestability". It is a demystification indicating that the common sense thinking "is a closed system that does not have the built-in imperative of seeking the truth by sacrificing the convenient beliefs" (Czerwiński, 1986, p. 7). It is subject to an overriding restriction. It is a form of thought that cannot be sufficient; it cannot constitute itself into an autonomous system with sufficient cognitive performance (Czerwiński, 1986, pp. 910).

However, when the common sense and the common sense thinking are taken seriously, with the excessive honors, they become "the backbone of self-righteous ignorance, which often turn its aggression against thinking that operates with specialized tools and utilizes the critical procedures" (Czerwiński, 1986, p. 10). The common sense thinking "cannot set the program in cognitive issues. Such a program would inevitably mean autosterilization" (Czerwiński, 1986, p. 10).

Considering the role and importance of common sense thinking and its various manifestations, it is worth remembering that "however we belong to a civilization so heavily directed by science, we continue to live in the horizon of common sense thinking" (Czerwiński, 1986, p. 12). The common sense and common sense thinking concern not only ordinary people but sometimes even distinguished philosophers. No wonder that common sense thinking also influences the philosophical reflection on sport; it influences the people describing themselves as the philosophers of sport.

\section{Prominent philosophers and common-sense thinking}

Unfortunately, there are many examples of common-sense thinking among philosophers. This includes Aristotle, Georg Wilhelm Friedrich Hegel, Ludwig Wittgenstein, and Eugen Fink. All of them were unintentionally and inadvertently open to the influence of common-sense thinking, even though these philosophers - especially them - are ones who should have been (as they had substantive and methodological tools) particularly sensitive and immune to this type of speculation.

1. Common-sense thinking can be seen in Aristotle's considerations on free time as well as on the topic of space and time in general.

a) In speaking about free time, Aristotle claims in Nicomachean Ethics (Aristotle, 1956) that "free time doesn't mean the end of work. Quite opposite, work is the end of free time. Free time should be devoted to art, science, and philosophy above all". This is a common-sense definition and a wrong one at the same time, since from this definition eventuates - regardless of what is the end of what, and how far the value of free time is appreciated in this definition - that free time, similar to work time, is time that is not free from various occupations. On the contrary, it stems from the definition that free time should be busy and occupied by art, science, and philosophy. Hence, if free time is busy, it is not free. It must be noted that, although being occupied by artistic, scientific, and philosophical activities can be enjoyable, these activities are more or less related to time-consuming and exhausting work. I experience it myself as I deal with theater, philosophy, and teaching (Kosiewicz, 2012, p. 78).

I will stress once again that everything that we do, we do in our free time, that is, free from other activities, which are - or are not - related to our responsibilities. Simply put, we are not able to do 
anything in additional to what we do in the time that is already occupied with some activities (Kosiewicz, 2012, p. 78).

Even if we spend time pleasantly, it is time filled with pleasures. This is not time that is free from pleasure, but instead is time filled with pleasures; that means it is busy time, and not free time. Therefore, the next pleasurable or other activities can take place after the preceding are finished; that is, they can take place in the free time from the past activities.

In this sense, free time means only that it is not a time occupied by anything else. Unfortunately for individual people (the concept of free time refers to them), there is no such time that is not occupied by anything absorbing body or psyche (consciousness or subconscious), or man in general. We are always dealing with time that is occupied. Incidentally, all the concepts of free time that assume a subject can function in the area (dimension) of unoccupied time have a common-sense character, regardless of the context of justification. The justification includes arguments that endeavor to validate the intuitive point of view publicized by Aristotle, which, after Aristotle, became a common point of view.

b) Aristotelian Physics (2010), as opposed to Metaphysics (1983), has a lot of common-sense, colloquial, and even banal statements such as:

"If any movement is done in time and at any time there is a possibility of movement, and everything that moves, can move faster and slower, therefore, at any time the movement can be faster and slower" (Aristotle, 2010, p. 215);

or, "A faster body will travel the same distance in shorter time than a slower body" (Aristotle, 2010, p. 216).

The quotations seen above and the related context of justification have a common-sense character (but it was probably a cutting-edge discovery for Aristotle). The quotations contain true sentences true from the point of view of physics and assumptions of classical (Aristotelian) logic - but they have a common-sense character even though the Stagirite was an obvious genius.

Also, more common sense than philosophical character echoes from another quote on the relationship between space and time:

The quantity of space and time are subject to this division. And if one of these values "is infinite, then the second is such, whereby both are infinite in the same manner, for example, if the time is infinite because of its ends, also the length will be infinite with regards to it ends; if the time is infinite with regards to its divisibility, also the length will be infinite with regards to its divisibility; and if the time is infinite because of the one and the other, it will also be a case with regards to the length" (Aristotle, 2010, p. 216).

Unfortunately, beyond common-sense associations, we would not get any new information about the nature (the essence and the properties) of time or space from this statement. This applies to almost all Physics (2010), as opposed to Metaphysics (1983).

Incidentally, in the quote above Aristotle used the terms "division" and "length" in the colloquial sense in relation to both time and space. Space and time are described through separate "divisions". The measurements of space include the length, width, and height (and, perhaps in the future, some other dimensions), while the measurement of time is determined by other conventions that take into account its passage or duration (not the width, height, or length) - dependently and independently from the infinity of both dimensions, which is a possibility in both cases.

2. Martin Heidegger, when considering the relationship and the properties of being and time, noted that Georg Wilhelm Friedrich Hegel was not immune to common-sense thinking. This is shown in Heidegger's 
fundamental work, Being and Time (1994). Heidegger claimed (1994, p. 601) that "Hegel with his concept of time bestirs utterly towards the common sense understanding of time". In Heidegger's opinion, this is proved by the following passage from the Encyclopedia of the Philosophical Sciences (1990), in which Hegel stated that:

"Time, as the negative unity of being outside of itself, is just as thoroughly abstract, ideal being: being which, since it is, is not, and since it is not, is. But time itself is this becoming, which rely on fact that the differences, (although absolutely instantaneous, that is, directly undergoing negation) are defined as being external, that is, in any case external, even if only towards themselves" (Hegel, 1990, § 258).

In his long elaboration, the German hermeneutic philosopher wrote that Hegel's characterization of the time assumed on the basis of "now" that the time is, with regards to its full structure, covered and annihilated, so that it can be viewed only as something "perfectly" present (Heidegger, 1994, p. 601).

Incidentally, unlike in Hegel's views, all antiquarian (pre-Aristotelian) concepts of time (and Aristotle's reflection on time, with the exception of statements contained in his Physics) "do not contain - as I think - an interpretation of time in the common-sense spirit" (Kosiewicz, 2012, pp. 77-94). This applies even to those ideas that introduced, to a greater or lesser extent, the idea of "the Absolute, which was brilliantly developed and introduced in the early nineteenth century by the German idealist" (Kosiewicz, 2012, pp. 88-89).

3. Ludwig Wittgenstein, in pondering the concept of "game" in his Philosophical Investigations (2000), said that, due to the variety of phenomena, it is impossible to define this concept that can be assigned by that name. However, for two reasons, it is a common-sense hypothesis:

a) The ultimate definition of game cannot be formulated, but not because there is a large and constantly growing number of the variety of different games. For that reason, it would not be possible to define the concept of "human being" because no two individuals are identical. Everyone is different. The ultimate definition of game cannot be formulated mainly because definitions from the area of humanities will never have the optimal shape and content - that is, one that is universally accepted by all. This applies, for example, to the concept of culture, religion, theater, politics, and philosophy. We are constantly creating - for different reasons, among which are operational (in terms of research) reasons - new versions of existing definitions.

b) The Wittgenstein view concerning the impossibility of formulating an ultimate definition contradicts the concept of Platonic ideas that refers to types, species, subtypes, or classes of entities. The concept of the Platonic idea can be thought as the comprehensive, general definition relating to all specific entities of both the abstract and material characteristics. Because it has ontological features, we are dealing in this case with a concept that is the definition in the form of an ontological entity. This is not a definition of semantic and anthropocentric overtones formulated by human beings. In contrast to the semantic conceptualizations, Plato's definition is one, unchanging, perfect, and ideal entity that includes all past, present, and future concretizations of both an abstract and material nature, regardless of their diversity, variety, and quantity. The ontological definition, which applies and generally characterizes all existing and possible, abstract and material phenomena, concerns - according to the second definition of philosophy in Pseudo-Plato's views - what is true and shows how it is true. This definition is an indisputable truth (Domański, 1996, p. 6).

4. The error that is typical of common-sense thinking also appears in the views of Bernard Suits contained in a short monograph The Grasshopper: Games, Life and Utopia (1978). The author comments on the Wittgenstein impossibility of creating the definition of game. He claims that Wittgenstein gave up too soon on deeper research on the concept of game, that he "didn't look carefully enough" (Suits, 1978). Now, no 
matter how long Wittgenstein had been studying the issue, he would not have been able (for the reason that we have identified above) to formulate the optimal and ultimate definition of game. This is not possible in the humanities due to the ever-changing contexts of content, as well as the ever-changing cultural, civilizational, axiological, and interpretative context, due to new projects that require new approaches and new theoretical and methodological instruments.

Plato's theory of ideas, although it presents a possible interpretation that refers to the history of philosophy, will not become the philosophical or methodological foundation for the formulation of the modern theory of definition. But the possibility of its application seems interesting sometimes.

\section{Philosophers of sport and common-sense thinking}

The influence of common-sense thinking and common sense is also to be seen in the philosophy of sport, especially in the statements of people describing themselves - and defined as such by others - as philosophers of sport. There are many examples of that. This includes Hennig Eichberg, Jim Parry, Claudio Tamburini, Runar Gilberg, Gunnar Breivik, and Sigmund Loland, as well as William J. Morgan, and Bernard Suits. Today, I will focus only on the common sense ideas related to the reflection on the philosophy of sport in general, and on the contributions of Henning Eichberg and Jim Parry in particular.

1. It is a strictly common-sense procedure to describe all philosophical statements about sport as the philosophy of sport in the strict sense. It is a schematic activity, theoretically superficial - but used for a good cause to provide order and to consolidate the manifestations of cognitive reflection.

The philosophy of sport doesn't arise as a result of the fact that some philosopher or other person, such as a physical education teacher, educator, sociologist, psychologist, theorist of sports doctor, or a journalist, is considering an issue related to sports. It doesn't appear as a result of someone trying to deal with some sports-related problems from the perspective of more or less important, shallow, or deeper philosophical issues, assumptions, questions, hypotheses, or theories. To consider these issues doesn't automatically make the person considering them a philosopher of sport.

In the first case, the fact that the philosopher talks about sport does not imply - taking into account the level of these considerations (but we will elaborate on this issue later) - that we are dealing with the philosophy of sport, but only that this is a philosophical reflection on sport. However, common-sense and everyday understanding of such activities suggests - unfortunately, incorrectly - that we are dealing precisely with the philosophy of sport. Some examples in this regard are the statements of Stanisław Kowalczyk, who is one of the greatest Catholic philosophers in Poland, and whose achievements are enjoying universal recognition (Kowalczyk, 2002). Many times I have polemicized regarding his positions.

In the second case, common sense and common-sense thinking suggest that even a person who doesn't have an adequate philosophical preparation or appropriate and sufficient professional, philosophical competence, but nonetheless refers to some philosophical statements, or who uses in a superficial way nonempirical assumptions of social sciences, could be named a philosopher of sport.

In the first case, this philosophical reflection on sport cannot be yet called philosophy of sport, because the condition of the appropriate maturity of the discipline has not been met. There is, in fact, a lack of substantive and methodological assumptions (from the area of exact methodology) that would be typical only for this autonomous philosophical discipline. The evidence of maturity of the exact scientific discipline and also the testimony of its autonomy in relation to the other disciplines is the occurring and potential impact and feedback of this discipline on general and exact methodology, as well as on the assumptions and substantive issues of general philosophy and the exact philosophies.

In the second case, the fact that someone - more or less random - plays ball in his backyard does not imply that he is a professional and competent player. Thus, from the fact that someone - more or less random - raises philosophical issues (including issues related to sport) does not stem that he is a philosopher 
or a philosopher of sport. It should also be noted that one couldn't be a philosopher of sport if the activity he conducts cannot be called philosophy of sport for substantive and methodological reasons. If the philosophy of sport sensu stricto does not exist yet, then one cannot be a philosopher of sport in the truest sense. What exists are philosophical reflection on sport and the people who use - more or less competently - philosophical tools for considerations and research on sport.

2. Hennig Eichberg publishes his papers in the journal Sport, Ethics and Philosophy. Published in the journal was his book on the topic of body culture. I will refer mostly to his presentation, which he gave as a keynote speaker on the $10^{\text {th }}$ European Association for the Sociology of Sport Conference. The presentation was entitled Play as Production - Production as Game? Towards a Critical Phenomenology of Productivity. In his presentation, Hennig Eichberg argued, that Danes constitute a chosen and unique nation. His arguments were related to the concepts of play and game. In this case, it was about the autotelic behaviors, in the form of play such as board game or field play that provides pleasure. Johan Huizinga describes these behaviors as "ludic". The term is derived from title of his book Homo ludens. The ludic, play-spirit activities can also fulfill other functions - for example, cathartic, escapist, aesthetic, hedonistic, recreational, or cognitive functions of the autotelic overtones.

H. Eichberg, a German-born naturalized Dane, stated, "Denmark can be named the land of play", and "Denmark produces play and plaything for the world". Nota bene, Grant Jurvie from the University of Stirling, when describing many interesting folk games of Scottish Highlanders, has not rushed to suggest to others the idea that Scotland is the fatherland of games and play for all Highlanders in the world.

Also the Chinese people could be confidently called the manufacturers of playthings (toys) and play for the whole world, because they manufacture everything at the small price and their products are enormously popular.

In 2000, in Brisbane, I bought an Australian boomerang to play it with my 9-year-old son. In Poland, I noted the inscription on it: "Made in China".

To draw hasty conclusions - as in the case of Eichberg and many others - has a common-sense character. It is associated with schematic thinking, resulting from adherence to a particular nation and perceiving it as having special and unique features that set this nation apart from others. It also results from the need to communicate this message to other nations, to announce that this particular nation has given the world something that the world would never have invented and created.

3. The quasi-methodological presentation of Jim Parry, who call himself a philosopher of sport, during the IAPS Conference in Fullerton in 2013 can also serve as an example of common-sense thinking. Parry categorically denied the need for research from the area of sociology and psychology of sport, which would confirm the hypothesis indicating that players' aggression in noncontact sports during competition is lower than in contact sports. He said that since the hypothesis seems to be very likely to be confirmed, the research is not necessary. Well, every hypothesis must be tested in order to know - that is, to confirm or falsify - its logical value. Without the necessary research, the hypothesis will be only the manifestation of commonsense thinking, indicating that the reality is as it seems to us or another group of people. This kind of thinking is irrelevant to the cognitive investigation of aggression in sports as it is only a manifestation of a presumption with common-sense overtones.

The aforementioned philosopher of sport also claimed that instead of empirical research, it is enough to formulate a philosophical hypothesis. Now, the logical value of philosophical hypotheses also needs to be checked (tested) and its content should be confirmed (or not) with the appropriate methodological context. If this is not done, then we are dealing with a common-sense hypothesis, even though it has been formulated by the philosopher. Nota bene, speculative philosophy cannot and should not replace the easy-to- 
perform empirical research in social sciences such as sociology and psychology. Even the suggestion to replace empirical research with philosophical hypothesis seems quite surprising and highly unreasonable.

Moreover, what seems obvious from a common-sense point of view doesn't have to be true. It was proved, for example, by a study of Niels van Quaquebeke and Steffen R. Giessner (Quaquebeke, \& Giessner, 2010, pp. 3-32; Kosiewicz, 2014, pp. 44-45). During their seven-year study on football matches in the German Bundesliga, the UEFA Champions League, and FIFA World Cups (Quaquebeke, \& Giessner, 2010, p. 14), they adopted a statement, which was quite probable from the point of view of common-sense thinking, that more fouls are performed by taller players than by their shorter victims. It turned out, however, that foul play more often was targeted at the taller players. The smallest players fell down more often. They also frequently suggested (pretended) that they were hurt by the opponent. The conducted research contested the common-sense opinion and the related hypothesis that was based on common sense. The research brought surprising and different from expected results.

To conclude, it can be stated that common-sense thinking and common sense are considered a widespread phenomenon that occur in different social and professional groups with stronger or weaker concentration. Accordingly, the phenomenon influences verbal communication on a day-to-day basis. Despite having a smaller impact on research activity, its influence cannot be avoided. Among other scientific fields, philosophical research on nature represents the confirmation, characteristics and examples of the phenomenon. In all probability, the influence of common-sense thinking can only be eliminated in formal science, for instance mathematics. On the other hand, this does not concern philosophers themselves, although they are aware of the negative consequences of this para-cognitive form of activity. Beyond their academic, educational and scientific activities, they use informal and subjective language full of personal point of views, which spreads the idea of freedom of thought. Unintentionally, informal language is reaching professional relationships, as well as verbal and written communication. It negatively influences cognitive narration, and supports the proclamation of certain truths that lack evidence and are short of rational and empirical context.

In addition, this kind of fault may also be found in the works of the undersigned, who would indicate this in order to avoid making such faults in the future. Unfortunately, however, he - the same as others - does not have the capability to notice some of his own mistakes.

\section{REFERENCES}

Arystoteles (1956). Etyka nikomachejska /Nicomachean Ethis/. Warszawa: PWN.

Arystoteles (1983). Metafizyka /Metaphysics/. Warszawa: PWN.

Arystoteles (2010). Zachęta do filozofii. Fizyka /Encouragement to Philosophy. Physics/. Warszawa: PWN.

Czerwiński, M. (1986), Przedmowa /Prefice/. In T. Hołówka (Ed.), Myślenie potoczne /Common Sense Thinking/. Warszawa: PIW.

Domański, J. (1996). Metamorfozy pojęcia filozofii. Od antyku do renesansu /Metamorphoses of the Notion of Philosophy. From Antiquity to Renaissancel. Warszawa: Polska Akademia Nauk Instytut Filozofii i Socjologii PAN.

Grave, S.A. (1960). The Scottish Philosophy of Common Sense. Oxford: Oxford University.

Hegel, G.W.F. (1990). Encyklopedia nauk filozoficznych /Encyclopedia of the Philosophical Sciences/. Warszawa: PWN, § 258.

Heidegger, M. (1994). Bycie i czas /Being and Timel. Warszawa: PWN.

Hołówka, T. (1986). Myślenie potoczne /Common Sense Thinking/. Warszawa: PIW.

Huizinga. J. (2011). Homo Ludens. Warszawa: Aletheia.

Kosiewicz, J. (2012). Free Time versus Occupied and Unoccupied Time in a Philosophical Context. Physical Culture and Sport. Studies and Research, 55(1), 77-94. DOI: 10.2478/v10141-012-0015-2.

Kosiewicz, J. (2014). Foul Play in Sport as Phenomenon Inconsistent with the Rules, yet Acceptable and Desirable: Ethical Conditions. Physical Culture and Sport. Studies and Research, 62(1), 32-47. DOI:10.2478/pcssr-2014-0010. 
Kowalczyk, S. (2002). Elementy Filozofii $i$ teologii sportu/Elements of the Philosophy and Theology of Sport/. Sandomierz: Wydawnictwo Diecezjalne.

Reid, T. (1764). Inquiry into the Human Mind on the Principles of Common Sense. Dublin: Printed for Alexander Ewing.

Reid, T. (1975). Rozważania o władzach poznawczych człowieka /Essays on the Powers of the Human Mind/. Warszawa: PWN.

Quadsnquebecke van, N., \& Giessner, S.R. (2010). How Embodied Cognition Affects Judgments: High-Attribution Bias in Football Foul Calls. Journal of Sport \& Exercice Psychology, 32(1), 3-32.

Suits, B. (1978). The Grasshopper: Games, Life and Utopia. Toronto, Buffalo: University of Toronto Press.

Wittgenstein, L. (2009). Philosophical investigations. Malden, MAU [etc.]: Wiley-Blackwell Publishing.

AUTHOR'S ADDRESS: $\quad$ Jerzy Kosiewicz

Department of Philosophy, Chair of the Social Sciences

Josef Pilsudski University of Physical Education in Warsaw

Marymoncka 34

00-968 Warsaw, Poland

E-mail: jerzy.kosiewicz@awf.edu.pl

Received: 1 February 2016; Accepted: 21 March 2016 